\title{
Joint network and route optimization in road evacuation
}

\author{
A. Polimeni \& A. Vitetta \\ Università degli Studi Mediterranea di Reggio Calabria, \\ DIMET - Dipartimento di Informatica, \\ Matematica, Elettronica e Trasporti, Italy
}

\begin{abstract}
In this paper a Network and Route Optimization Problem (NROP) in evacuation conditions is proposed. The variables involved in the problem are discrete (link topology, routes for rescue vehicles) and continuous (link capacity). The discrete variables are related to the link direction, lane numbers, lane use and sequence of users reached by rescue vehicles. The continuous variables, assuming that the link capacity is a function of the characteristics of the final node in the link, are related to the intersection control setting. The NROP is hence formulated as a mixed (discrete/continuous problem) in a congested network considering the ordinary demand and the evacuation demand. The network topology is optimized considering the users who evacuate on their own and the rescue vehicles that move to rescue some users. A heuristic procedure is used to find the best network configuration.
\end{abstract}

Keywords: continuous/discrete variables, heuristic approach, vehicle routing.

\section{Introduction}

The Network Optimization Problem (NOP) consists of finding the optimal configuration of an existing network optimizing some objectives. Initially, this problem concerned the link direction and lane allocation optimization (a discrete problem). It was then extended to capacity optimization (a continuous problem) defining a Mixed NOP (MNOP). The capacity optimization regards the optimization of the signal setting at intersections, known as Traffic Signal Setting Optimization (TSSO). 
The Vehicle Routing Problem (VRP) consists of finding the optimal set of routes respecting some constraints. The VRP, formulated initially to optimize the routes for a fleet of vehicles for freight transport, has been extended to other fields. Thus, the problem was extended to other vehicle classes, like vehicles for passenger transport or rescue vehicles. In this second case, two cases can be distinguished in relation to ordinary operations or emergency situations (i.e. in an evacuation).

In the transport field, the NOP and the VRP are generally treated separately and rarely to optimize vehicle routes in an evacuation, but they are closely connected. In this paper, a formulation trying to link the two problems is proposed. Moreover, the formulation is made in evacuation conditions, to optimize the travel time of users who evacuate on their own and the travel time of rescue vehicles that operate to rescue some users. Since in the literature the two problems are separated, below a literature review is developed separately for NOP and VRP and it is reported in Section 2.

The problem proposed in this paper is a Mixed Network and Route Optimization Problem (MNROP). The MNROP can aid in the evacuation of a city when a sudden event happens. In fact, a network optimization (i.e. number of lanes for each link, intersection regulation) can reduce significantly the evacuation time. In an evacuation, other impacts of network optimization can be considered, for example the lane reservation for rescue vehicles to create a lifeline that allows the movement in and out of the rescue vehicles. The negative side in a lifeline is the reduction of capacity devoted to other vehicles, which could exit from the area in a longer time compared to the scenario without a lifeline. Hence, it is necessary to have an arrangement between the two cases, to improve the rescue vehicle movements without compromising the evacuation of private users.

The MNROP is formulated and solved in evacuation conditions. The problem treated is related to link orientation, lane allocation and signal setting optimization to regulate the intersections and, hence, optimize the link capacity. The objective function defined is related to the total travel time spent on the network; others formulations are however possible.

In road evacuation (for general considerations, see [1]), the MNROP can be a means to help planning [2-6].

As reported, in this paper the original contributions are related:

- a mixed (discrete and continuous variables) network optimization problem is defined highlighting the link capacity optimization;

- the network optimization problem is connected with vehicle routing problems;

- the proposed approach is formulated in evacuation conditions.

The paper is structured as follows. In Section 2 a literature review is reported, considering a possible classification for the NOPs. In Section 3 the problem formulation is reported; this section is divided in two sub-sections, related to the models and the algorithms. Finally, in Section 4, the conclusions and possible future developments are reported. 


\section{Literature review}

This section is made up of two subsections: in the first the NOP is treated, in the second the VRP is reported.

Various characteristics can be considered in NOPs, related to the variables, the objectives, the demand and so on.

The first classification refers to the variables type, considering: (i) problems with discrete variables (DNOP, Discrete NOP), (ii) problems with continuous variables (CNOP, Continuous NOP) and (iii) mixed problems (both discrete and continuous variables, MNOP, Mixed NOP). This classification must pay attention to the continuous case, which has various conflicting treatments in the literature. In fact, frequently the problem is tackled as a link width optimization problem not considering: (1) the intersection optimization, (2) that the link width depends on lane allocation and hence is a discrete problem, (3) that link widening is strictly tied to the lane addition (i.e. for provision of constraints). Hence, below when the continuous problem is tackled, the problems concerning the signal setting optimization are considered.

In the discrete field, Billheimer and Gray [7] propose an approximate algorithm (based on insertion and deletion of links in the network) to solve the NOP; the original algorithm is applicable only to uncongested networks, but can be extended to congested cases. Xie and Turnquist [8], in evacuation conditions, define a problem to optimize the network with the aim of optimizing a lifeline reserving some lanes to rescue vehicles and giving them priority at intersections. In Chen and Alfa [9] a heuristic branching algorithm is proposed for solving NOPs considering the congestion. In emergency conditions, Kalafatas and Peeta [10] propose a model to enhance the capacity of some links using contraflow strategies and lane additions. Other papers with discrete variables can be considered, such as [11-13].

In the continuous field, the NOP can be formulated as a TSSO [14], considering also two other aspects [15]: path choice (rigid or elastic) and interacting junctions (with or without coordination optimization). Considering the rigid path choice, the analysis may be on a single junction [16] or on a network of interacting junctions, optimizing offset [17]. In [18-21] an approach with elastic path choice and isolated junctions is considered, while in [22, 23] interacting junctions are considered. Some works deal with the problem in a continuous approach [24-30], but they can be traced back to the discrete approach. Other papers with continuous variables can be considered, such as [31-33].

In the mixed field, Cantarella et al. [15] propose some heuristics approaches to optimize the link topology and light traffic at the intersections, minimizing the total cost in the network. A heuristic approach is proposed in [34] to solve the NOP considering topological variables and signal setting parameters, without changes in infrastructural resources. A three-step method is proposed in [35] to 
select, considering some criteria, the best network configuration: first a topological similarity evaluation between solutions is performed, second, cluster formation is carried out, thirdly, selection of the best solution in the clusters is made. In Table 1 some papers classified by considering the aspects described above are reported. Other authors propose some NOP formulations based on other problem aspects. Miandoabchi and Farahani [36] define a problem with rigid demand, the aim being to maximize the reserve capacity. Chiou [37] propose a problem supposing that the link equilibrium flow is a function of link capacity and that this function is derivable to apply a gradient-based resolution method. Moreover, a further characteristic can be made considering the demand, rigid [7, 8-13] or elastic [38] A further approach considers the infrastructural resources given [7] or considers the possibility of strengthening the infrastructural resources (i.e. building new streets or widening some existing streets) respecting a budget constraint [36]. Other considerations can be made on the objective; some papers consider a single objective [10,11-36], others a multi-objective problem $[38,39]$. Other papers [40, 41] propose an approximation in the problem formulation to solve it more easily; nevertheless the solution is not exact for the original problem.

Table 1: NOP classification: some papers in the literature.

\begin{tabular}{cccccc}
\hline Reference & Variables & Demand & $\begin{array}{c}\text { Infrastructural } \\
\text { resources }\end{array}$ & Objective & Conditions \\
\hline$[7]$ & $\mathrm{D}$ & $\mathrm{R}$ & $\mathrm{F}$ & Mono & Or \\
{$[8]$} & $\mathrm{D}$ & $\mathrm{R}$ & $\mathrm{F}$ & Mono & Ev \\
{$[10]$} & $\mathrm{D}$ & $\mathrm{R}$ & $\mathrm{F}$ & Mono & Ev \\
{$[11]$} & $\mathrm{D}$ & $\mathrm{R}$ & $\mathrm{V}$ & Mono & Or \\
{$[13]$} & $\mathrm{D}$ & $\mathrm{R}$ & $\mathrm{V}$ & Mono & Or \\
$\ldots$ & $\ldots$ & $\ldots$ & $\ldots$ & $\ldots$ & $\ldots$ \\
{$[20]$} & $\mathrm{C}$ & $\mathrm{R}$ & $\mathrm{F}$ & Mono & Ev \\
{$[21]$} & $\mathrm{C}$ & $\mathrm{R}$ & $\mathrm{F}$ & Mono & Or. \\
$\ldots$ & $\ldots$ & $\ldots$ & $\ldots$ & $\ldots$ & $\ldots$ \\
{$[15]$} & $\mathrm{M}$ & $\mathrm{R}$ & $\mathrm{F}$ & Mono & Or \\
{$[34]$} & $\mathrm{M}$ & $\mathrm{R}$ & $\mathrm{F}$ & Mono & Or \\
{$[35]$} & $\mathrm{M}$ & $\mathrm{R}$ & $\mathrm{F}$ & Multi & Or \\
{$[38]$} & $\mathrm{M}$ & $\mathrm{E}$ & $\mathrm{F}$ & Multi & Or \\
$\ldots$ & $\ldots$ & $\ldots$ & $\ldots$ & $\ldots$ & $\ldots$ \\
\hline
\end{tabular}

D: Discrete, C: Continuous, M: Mixed; E: Elastic, R: Rigid, F: Fixed, V: Variable, Mono: Monoobjective, Multi: Multi-objective, Or: ordinary, Ev: Evacuation.

The NOP was formulated also for transit system optimization considering the optimization of lines [42] and optimal frequencies [43]; line and frequency optimization can be considered simultaneously [44].

General considerations in the NOP field can be found in [45-47]. 
The VRP concerns the necessity to visit a certain number of users optimizing the user sequence, leaving from an origin and returning to it with respect to some constraints and optimizing an objective function. The field of VRP is extensive, and a large number of works tackle the problem. A first classification can be made considering the solution approach, exact [48] or heuristic [49].

Another classification element can be the type of vehicles considered: freight vehicles or rescue vehicles. Moreover, considering the rescue vehicles, if they operate in ordinary conditions or in emergency conditions can be evaluated.

In emergency conditions, Shen et al. [50] propose a two-stage model: at the first (planning) the routes are generated in advance, at the second (operation) changes are made to the routes considering the changes in the supply. In Araz et al. [51] a model to maximize the number of users rescued minimizing the evacuation time is proposed. Similarly, Liu et al. [52] propose a formulation to maximize the served demand and minimize time delays in the distribution of medical supplies.

\section{Problem formulation}

Figure 1 shows the proposed approach for MNROP. Two stages can be considered: the first is the MNOP, the second the VRP.

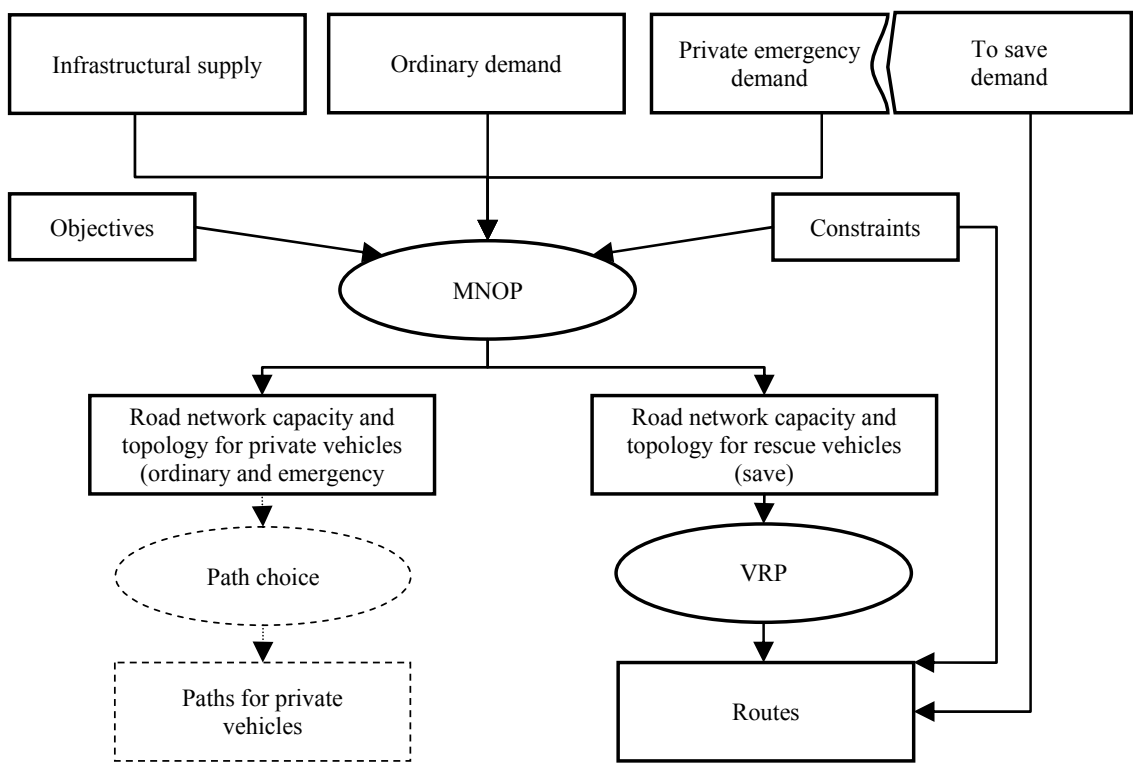

Figure 1: Proposed approach for network and route optimization.

The network optimization needs as inputs the infrastructural supply and the demand. The infrastructural supply is represented by the infrastructural resources 
available (streets). It must also consider that in emergency conditions some infrastructural resources may not be available. The demand has two main components: the ordinary demand is the travel demand that moves on the network during a typical day; the emergency demand is the demand that moves on the network when a sudden event imposes the evacuation of the people. To study in depth the demand analysis, refer to [53-57]. In ordinary cases to simulate the system the classical approach of transport theory (distribution, modal choice, path choice and so on) can be used; in emergency cases this approach must be altered to consider the modification in the system and in the demand (i.e. the destination is blocked). The emergency demand can be divided into two parts: the first related to the users who evacuate on their own (private emergency demand), the second related to the users who need help to evacuate (to save demand). Considering the problem objectives and constraints a model for network optimization is proposed (Section 3.1) and solved with a genetic algorithm (Section 3.2). This procedure allows one to find the optimal network configuration both for user who in an evacuation leave the area on their own (optimal private network or ordinary line) and for users who need help to leave the area (optimal rescue vehicles network or lifeline). The outputs are the public network topology and the optimal regulation in the junctions (also ordinary line) and the rescue vehicle network, with some lanes reserved for emergencies (lifeline). With the public network is defined the road network which can be used by all users to evacuate the area; with the rescue vehicle network is defined the network portion reserved for rescue vehicles.

The network optimization has as output the network capacity and topology for private and rescue vehicles. At this level, the private users can choose the path they follow to leave the area and the rescue vehicles need to optimize the routes to rescue the users. Two cases can be considered for private users: the users are on a path that is constrained or can be choose the path. In the first case, the disaster manager chooses the path for the vehicles; in the second case the users choose the best (perceived) path. The path choice can be influenced by external messages, which can induce the driver to choose a path instead of another. The path choice for private users is not treated in this paper; the focus is on route optimization. Hence, the next stage is, considering the optimal rescue vehicle network, to solve a vehicle routing problem for rescue vehicles that rescue some users (Sections 3.1 and 3.2).

In the next sections, the proposed models and algorithms are reported.

\subsection{Model}

Two models are considered in this section: the first regards the network optimization and the second the route optimization.

The proposed NOP allows minimization of the total time spent in the network optimizing the street orientation, the lane numbers and the light traffic. Moreover, the optimal configuration of links reserved for the rescue vehicles is considered. 
The proposed route optimization model allows the minimization of the route cost for rescue vehicles, prioritizing the use of reserved lanes. This approach can be extended to other fields (i.e. freight distribution, [59]).

\subsubsection{Network optimization}

The NOP model is based on equilibrium concepts, since the link costs considered are the costs related to the equilibrium point of an assignment problem.

The following notation is used:

- $\mathbf{f}^{\mathrm{ORD}}$ is the ordinary flow vector, with entry $\mathrm{f}^{\mathrm{ORD}}{ }_{\mathrm{i}}$ the flow due to the ordinary demand;

- $\mathbf{f}^{\mathrm{EME}}$ is the emergency flow vector, with entry $\mathrm{f}_{\mathrm{i}}^{\mathrm{EME}}$ the flow due to the emergency demand;

- $\mathbf{f}$ is the total flow vector, the weight sum between the ordinary and emergency flows $\left(\mathbf{f}=\mathbf{f}^{\mathrm{ORD}}+\mathbf{f}^{\mathrm{EME}}\right)$;

- $\quad \mathbf{c}$ is the link cost vector, with entry $c_{i}$ the cost on the link $i$ (the cost $c_{i}$ depends on the link i characteristics and, in general, on the flow vector f);

- $\mathbf{y}$ is the configuration variables;

- $\gamma$ is the homogenization coefficient;

- $\zeta(\mathbf{f})$ is the objective function.

The problem is formulated as a minimization problem, as follows.

Minimize

$$
\zeta(\mathbf{f})=\sum_{\mathrm{i}=1 \ldots 1} c_{\mathrm{i}}\left(\mathbf{f}^{*}, \mathbf{y}\right) \cdot\left(\mathbf{f}_{\mathrm{i}}^{* \mathrm{ORD}}+\gamma \mathbf{f}^{* \mathrm{EME}}{ }_{\mathrm{i}}\right)
$$

where the elements with the superscript "**" are the result of a user equilibrium assignment.

The optimization variable is the vector $\mathbf{y}$. The problem constraints are related to the:

- network connection;

- node equilibrium;

- structural constraints.

The objective function (1) is expressed as minimization of total travel time spent on the network; the costs and the flows considered are those obtained with an equilibrium assignment.

\subsubsection{Route optimization}

The route optimization model is formulated as a VRP, in which the network and the link costs are those obtained solving problem (1). The link costs are flow dependent if the link is used by both private vehicles and rescue vehicles, and constant if the link is only used by rescue vehicles.

The following notation is used:

- $z_{\mathrm{ij}}$ is the cost of the shortest path between node $\mathrm{i}$ and node $\mathrm{j}$;

- $\mathrm{K}$ is the generic route;

- $\eta_{\mathrm{i}, \mathrm{K}}$ is the binary variable equal to one if the path between $\mathrm{i}$ and $\mathrm{j}$ belongs to route $\kappa$, zero otherwise;

- $\xi$ is the objective function. 
The routing problem is formulated as follows.

Minimize

$$
\xi=\sum_{\kappa} \sum_{\mathrm{i}} \sum_{\mathrm{j}} \mathrm{z}_{\mathrm{ij}} \cdot \eta_{\mathrm{ij}, \mathrm{K}}
$$

The problem constraints are the classical vehicle routing and can be summarized as:

- only one vehicle can visit a node;

- all routes leave from a refuge area and come back to it;

- capacity.

The optimization variables are the routes $\kappa$.

\subsection{Algorithms}

Both the network optimization and the route optimization problems are solved using heuristic procedures.

\subsubsection{Network optimization}

The genetic algorithm implemented to solve the NOP is that proposed in [15]. The genetic algorithm, starting from an initial population, randomly generated, evolves the population for a fixed iteration number. The population evolution is performed using the crossover and the mutation operators. A solution represents a network configuration; each solution generated can be admissible. The admissibility is verified with a connection test to evaluate that all centroids are reachable. The connection test is performed using the Dijkstra algorithm; the solution is considered connected if there exists at least a path between each o/d pair. Given an admissible solution, a procedure based on the Webster approach [16] is applied to optimize the traffic lights.

\subsubsection{Route optimization}

The route optimization is also performed using a genetic algorithm proposed previously in [58]. In this case, the genetic algorithm is used to solve a discrete problem (the variable $\eta_{\mathrm{j}, \mathrm{K}}$ of the problem (2) is a binary variable). A solution represents a sequence of users to visit respecting the constraints.

\section{Conclusions}

In this paper a model for network and route optimization in evacuation conditions is reported. A whole approach is proposed, considering two stages: first, the network is optimized (with lane allocation and link capacity optimization); second, route optimization is performed. Both problems are specified and solved with a genetic algorithm. In evacuation conditions, two scenarios are considered, regarding whether or not to include lane reservation for rescue vehicles. 
Future developments consider the specification of a multi-objective problem to conjugate the total evacuation time for private users (which increases with lane reservation) and the routes cost (which decreases with lane reservation). Moreover, there are plans to extend the application to a real case.

\section{Acknowledgement}

This work was partially supported by national MIUR under PRIN2009 grant no. 2009EP3S42_001.

\section{References}

[1] Russo F. and Vitetta A., Risk evaluation in a transportation system. International Journal of Sustainable Development and Planning, 1 (2), pp. 170-191, 2006.

[2] Russo F. and Rindone C., Safety of users in road evacuation: planning internal processes and guidelines. WIT Transactions on the Built Environment, Volume 96, Urban Transport XIII, Urban Transport and the Environment in the 21st century, Brebbia C. A. (ed.), WIT Press, Southampton, pp. 825-834, 2007.

[3] Russo F. and Rindone C., Safety of users in road evacuation: the logical framework approach in evacuation planning. WIT Transactions on the Built Environment, Volume 101, Urban Transport XIV, Urban Transport and the Environment in the 21st century, Brebbia C. A. (ed.), WIT Press, Southampton, pp. 751-760, 2008.

[4] Russo F. and Rindone C., Safety of users in road evacuation: Modelling and DSS for LFA in the planning process. WIT Transactions on Ecology and the Environment, Volume 120, Sustainable Development and Planning IV, vol.1, Brebbia C. A. (ed.), WIT Press, Southampton, pp. 453-464, 2009.

[5] Russo, F. and Rindone C., The planning process and logical framework approach in road evacuation: a coherent vision. WIT Transactions on the Built Environment, Volume 117, Safety and Security engineering IV, Guarascio M., Reiners G. Brebbia C. A. and Garzia F. (ed.), WIT Press, Southampton, pp. 415-425, 2011.

[6] Russo, F. and Rindone C., Planning in road evacuation: classification of exogenous activities. WIT Transactions on the Built Environment, Volume 116, Urban Transport XVII, Urban Transport and the Environment in $21^{\text {st }}$ Century, Pratelli and Brebbia C. A. (ed.), WIT Press, Southampton, pp. 639-651, 2011.

[7] Billheimer J.W. and Gray P., Network design with fixed and variable cost elements. Transportation Science, 7, pp. 49-74, 1973.

[8] Xie C. and Turnquist M.A., Integrated evacuation network optimization and emergency vehicle assignment. TRB 2009 Annual Meeting, 2009. 
[9] Chen M. and Alfa, A.S., A network design algorithm using a stochastic incremental traffic assignment approach. Transportation Science, 25(3), pp. 215-224, 1991.

[10] Kalafatas G. and Peeta S., Planning for evacuation: insights from an efficient network design model. Journal of infrastructure systems, 15(1), pp. 21-30, 2009.

[11] Gao Z., Wu J. and Sun H., Solution algorithm for the bi-level discrete network design problem. Transportation research part B, 39, pp. 479495, 2005.

[12] Herrmann J.W., Ioannou G., Minis I. and Proth J.M., A dual ascent approach to the fixed-charge capacitated network design problem. European Journal of Operational Research, 95, pp. 476-490, 1996.

[13] Solanky, R. S., Gorti J. K. and Southworth F., Using decomposition in large-scale highway network design with a quasi-optimization heuristic. Transportation Research B, 32 (2), pp. 127-140, 1998.

[14] Cantarella G. E. and Vitetta A., A multicriteria analysis for urban network design and parking location. Preprints of conference Tristan II., (ITALY), pp. 839-852, 1994.

[15] Cantarella G.E., Pavone G. and Vitetta A., Heuristics for urban road network design: lane layout and signal settings. European Journal of Operational Research, 175, pp. 1682-1695, 2006.

[16] Webster F. W., Traffic signal settings. Road Research Technical Paper no. 39, 1958.

[17] Cantarella G.E., Improta G. and Sforza A., Road network signal setting: equilibrium conditions. Concise Encyclopaedia of Traffic and Transportation Systems, M. Papageorgiou ed., Pergamon Press, pp. 366371, 1991.

[18] Sheffi Y. and Powell W. B., Optimal signal setting over transportation networks. Transportation Engineering, 109(6), pp. 824-839, 1983.

[19] Cascetta E., Gallo M. and Montella B., Optimal signal setting on traffic networks with stochastic equilibrium assignment. TRISTAN III, 1998.

[20] Marcianò F.A, Musolino G. and Vitetta A., Signal setting design on a road network: application of a system of models in evacuation conditions. WIT Transactions on Ecology and the Environment, Volume 141, Risk analysis VII \& Brownfields V, Brebbia C. A. (ed.), WIT Press, Southampton, pp. 443-454, 2010.

[21] Marcianò A. and Vitetta A., A genetic algorithm to solve the traffic signal setting design problem considering driver routing. In Proc of XIII Meeting of the Euro Working Group on Transportation, Padova (ITA), 2009.

[22] Allsop R.E., Some possibilities for using traffic control to influence trip destinations and route choice. In Proc of the Sixth International Symposium on Transportation and Traffic Theory. Buckley ed., Amsterdam, Elsevier, pp. 345-374, 1974. 
[23] Gartner N.H., Area traffic control and network equilibrium. Traffic Equilibrium Methods, Lecture Notes in Economics and Mathematical Systems, 118, M. Florian, ed., Springer-Verlag, Berlin, pp. 274-297, 1976.

[24] Gao Z., Sun H.Zhang H., A globally convergent algorithm for transportation continuous network design problem. Optim. Eng., 8, 241257, 2007.

[25] Chiou S. W., A generalizated iterative scheme for network design problem. Applied mathematics and computation, 188, pp. 1115-1123, 2007.

[26] Yang J., Xu M., Gao Z., Sensivity analysis of simulated annealing for continuous network design problems. Journal of transportation systems engineering and information technology, 9(3), pp. 64-70, 2009.

[27] Suwansirikul, C., Friesz, T.L., Tobin, R.L., 1987. Equilibrium decomposed optimization: a heuristic for the continuous equilibrium network design problem. Transportation Science, 21, 254-263.

[28] Boyce D. E., Ben Ayed O. and Blair III C. E., A general bilevel programming formulation of the network design problem. Transportation Research part B, 22, pp. 311-318, 1988.

[29] Friesz, T.L. and Shah S., An overview of nontraditional formulations of static and dynamic equilibrium network design. Transportation Research part B, 35, pp. 5-21, 2001.

[30] Meng Q., Yang H. and Bell M.G.H.,. An equivalent continuously differentiable model and a locally convergent algorithm for the continuous network design problem. Transportation Research B, 35, pp. 83-105, 2001.

[31] Teklu F., Sumalee A. and Watling D., A Genetic Algorithm Approach for Optimizing Traffic Control Signals Considering Routing. ComputerAided Civil and Infrastructure Engineering, 22, pp. 31- 43, 2007.

[32] Cascetta E., Gallo M. and Montella B., Models and algorithms for the optimization of signal settings on urban networks with stochastic assignment models. Ann. Operation Res., 144, pp. 301-328, 2006.

[33] Cipriani E. and Fusco G., Combined signal setting design and traffic assignment problem. European Journal of Operational Research, 155, pp. 569-583, 2004.

[34] Gallo M., D'Acierno L. and Montella B., A meta-heuristic approach for solving the urban network design problem. European Journal of Operational Research, 201, pp. 144-157, 2010.

[35] Russo F. and Vitetta A. A topological method to choose optimal solutions after solving the multi-criteria urban road network design problem. Transportation, 33, pp. 347-370, 2006.

[36] Miandoabchi E. and Farahani R. Z., Optimizing reserve capacity of urban road network in a discrete network design problem. Advances in engineering software, 42, pp. 1041-1050, 2011.

[37] Chiou S. W., Bilevel programming for the continuous transport network design problem. Transportation Research B, 39(5), pp. 361-383, 2005. 
[38] Cantarella G.E. and Vitetta A., The multicriteria road network design problem in an urban area. Transportation, 33, pp. 567-588, 2006.

[39] Miandoabchi E., Farahani R. Z., Dullaert W. and Szeto W.Y., Hybrid evolutionary metaheuristics for concurrent multi-objective design of urban road and public transit network. Networks and Spatial Economics, pp. 1-40, 2011.

[40] Poorzahedy H. and Turnquist M.A., Approximate algorithms for the discrete network design problem. Transportation Research part B, 16, pp. 45-55, 1982.

[41] Wang D.Z.W. and Lo H.K., Global optimum of the linearized network design problem with equilibrium flow. Transportation Research part $B$, 44, pp. 482-492, 2010.

[42] Ceder A. and Wilson N.H.M., Bus Network Design. Transportation Research B, 20, 331-344,1986.

[43] Russo F., Transit frequencies design for enhancing the efficiency of public urban transportation systems: An optimization model and an algorithm. Proceedings of the 31st ISATA Stuttgart. Automotive Automation Limited. Croydon, England, 1998.

[44] Gao Z., Sun H. and Shan L.L., A continuous equilibrium network design model and algorithm for transit systems. Transportation Research part B, 38, pp. 235-250, 2004.

[45] Oppenheim N., Urban Travel Demand Modelling. J. Wiley and Sons, New York, 1995.

[46] Bell M.G.H. and Iida Y., Transportation networks analysis. J. Wiley and Sons, New York, 1997.

[47] Cascetta E., Transportation System Engineering: Theory and Methods. Kluwer Academic Publishers, 2001.

[48] Fisher M.L., Optimal solution of vehicle routing problems using minimum k-trees. Operation Research, 42, pp. 626-642, 1994.

[49] Ando N. and Taniguchi E., Travel time reliability in vehicle routing and scheduling with time windows. Networks and Spatial Economics, 6, pp. 293-311, 2006.

[50] Shen Z., Dessouky M., and Ordóñez F., The stochastic vehicle routing problem for large scale emergencies, 2007. Source (last access06/12/2011):

bcf.usc.edu/ maged/publications/routing4LSE.pdf

[51] Araz C., Selim S., and Ozkarahan I., A fuzzy multi-objective coveringbased vehicle location model for emergency services. Computers \& Operations Research, 34, pp. 705-726, 2007.

[52] Liu Y., Chang G. L., Liu Y. and Lai X., A corridor-based emergency evacuation system for Washington D.C.: system development and case study. In TRB 87th Annual Meeting, Washington, D.C., 2008.

[53] Russo F. and Chilà G., Safety of users in road evacuation: demand models. WIT Transactions on the Built Environment, Volume 96, Urban Transport XIII, Urban Transport and the Environment in the 21st 
century, Brebbia C. A. (ed.), WIT Press, Southampton, pp. 773-782, 2007.

[54] Russo F. and Chilà G., Safety of users in road evacuation: RP vs. SP surveys in demand analysis. WIT Transactions on the Built Environment, Volume 101, Urban Transport XIV, Urban Transport and the Environment in the 21st century, Brebbia C. A. (ed.), WIT Press, Southampton, pp. 703-713, 2008.

[55] Russo F. and Chilà G., Safety of users in road evacuation: Modelling and DSS for demand. WIT Transactions on Ecology and the Environment, Volume 120, Sustainable Development and Planning IV, vol.1, Brebbia C. A. (ed.), WIT Press, Southampton, pp. 465-474, 2009.

[56] Russo F. and Chilà G., Demand models in road evacuation: a synopsis of recent contributions. WIT Transactions on the Built Environment, Volume 116, Urban Transport XVII, Urban Transport and the Environment in $21^{\text {st }}$ Century, Pratelli and Brebbia C. A. (ed.), WIT Press, Southampton, pp. 601-614, 2011.

[57] Russo F. and Chilà G., A statistical approach to analyse user behaviour in road evacuation. WIT Transactions on the Built Environment, Volume 117, Safety and Security engineering IV, Guarascio M., Reiners G. Brebbia C. A. and Garzia F. (ed.), WIT Press, Southampton, pp. 377-390, 2011.

[58] Vitetta A., Quattrone A. and Polimeni A., Safety of users in road evacuation: algorithms for path design of emergency vehicles. WIT Transactions on the Built Environment, Volume 101, Urban Transport $X I V$, Urban Transport and the Environment in the 21st century, Brebbia C. A. (ed.), WIT Press, Southampton, pp. 727-737, 2008.

[59] Russo F. and Comi A., A modelling system to simulate goods movements at an urban scale. Transportation, Volume 37, Issue 6, pp. 987-1009, 2010 . 